\title{
The buzz on mosquito, malaria genetic codes
}

In October announcements, two international teams of scientists reported sequencing the entire genomes of the malaria-carrying mosquito, and the malarial parasite itself. These breakthroughs will provide powerful tools to scientists struggling against malaria, which afflicts 500 million people worldwide and causes up to 2.7 million deaths annually (more than $90 \%$ in sub-Saharan Africa).

The simultaneous publications included a Science article detailing the genome of the mosquito Anopheles gambiae and a Nature article detailing the genome of the parasite Plasmodium falciparum. The Science article listed 123 authors, including three at UC Riverside; the Nature article listed 44 authors.

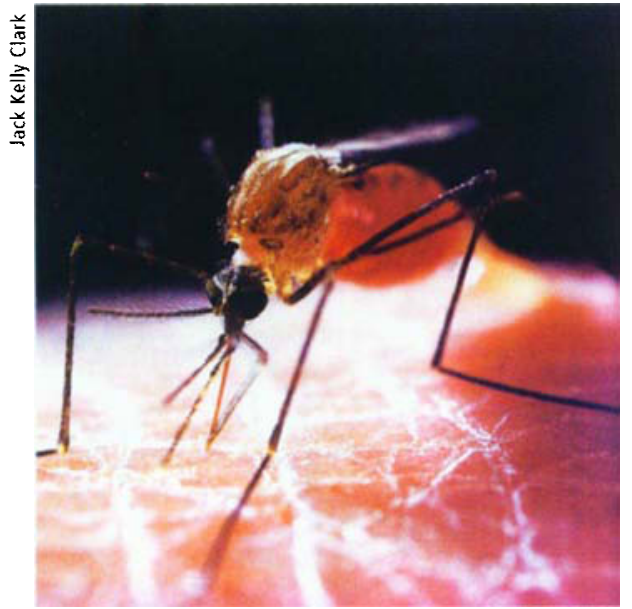

Sequencing of the mosquito genome could help to prevent malaria, which kills $\mathbf{2 . 7}$ million people annually. However, the scientific community was urged to use caution when pursuing genetic modification of insects.
"The economic cost to affected nations is immense," says Peter Atkinson, co-author and UC Riverside associate professor of entomology. "No vaccine has been developed for malaria. Understanding the genetic makeup of the mosquito that transmits malaria will help with the design of new strategies to fight this disease."

In addition to Atkinson, postdoctoral researcher Peter Arensburger and graduate student Lisa Friedli are co-authors of the Science paper, analyzing the genome for one class of transposable elements.

In the same issue of Science, UC Davis medical entomologist Thomas Scott and colleagues called upon the scientific community to use caution in applying this new knowledge to genetic modification of mosquitoes. With the release of the genetic sequences, they noted, scientists are now better able to explore the use of genetically modified, disease-resistant mosquitoes. Such mosquitoes could be used to breed with, and largely replace, their disease-causing counterparts in the wild.

If this new strategy is to succeed, however, the very basic ecology and population biology of mosquitoes needs to be better understood, Scott and colleagues wrote.

The October disclosures also came on the heels of a September announcement that the National Institutes of Health had awarded a 10-year, $\$ 4.3$ million research grant to Alexander Raikhel, UC Riverside entomology professor. The grant will support continuing investigation into the genetic and molecular mechanisms regulating egg devel- opment and maturation in mosquitoes. The research has implications for the prevention of deadly, mosquito-transmitted diseases, including malaria, West Nile virus and dengue fever.

\section{Centers to combat "agro-terror"}

UC Davis recently received two major grant awards to help combat "agro-terror" by protecting crop plants and food from contamination, disease, pests or pathogens, whether introduced accidentally or by terrorist acts.

A $\$ 900,000$ homeland security grant from the U.S. Department of Agriculture (USDA) will provide the initial funding for a new Western Center for Plant Disease and Pest Surveillance and Detection at UC Davis, coordinated by the College of Agricultural and Environmental Sciences. "Establishing an effective network for monitoring, detecting and diagnosing plant pests and diseases will be a challenging but vital task," says center director Richard Bostock, chair of the UC Davis plant pathology department.

And a new $\$ 5$ million center located at UC Davis, the Western Institute for Food Safety and Security, will facilitate a partnership between UC, the California Department of Food and Agriculture and the California Department of Health Services. "Our food supply is increasingly subject to contamination from both biological and chemical sources; and now we have the new threat of intentional contamination of food through bioterrorism," says Jerry Gillespie, institute director and UC Davis veterinary pathologist.

In September, a National Research Council report concluded that the United States is vulnerable to agricultural bioterrorism and needs a comprehensive defense plan. "Biological agents that could be used to harm crops or livestock are widely available and pose a major threat to U.S. agriculture," NRC committee chair Harley Moon of Iowa State University said. (The committee began its study prior to the September 11 attacks and the subsequent anthrax outbreak.) Over the past year, the federal government has allocated an additional $\$ 328$ million to USDA for homeland security programs to protect the food supply, including $\$ 43$ million for research to states and land-grant universities.

The plant-disease and pest network will concentrate on linking personnel, information systems and databases at diagnostic laboratories throughout the western region to better track the health of crops or the progression of a disease or insect outbreak.

The food safety institute's mission will be to develop the capability to identify food-borne hazards 
more rapidly and accurately, as well as methods to prevent natural and intentional food contamination. One area of emphasis will be the development of rapid diagnostic tests for disease-causing microbes such as Salmonella, deadly strains of E. coli, Cryptosporidium, anthrax and foreign foodborne diseases such as "mad cow disease."

\section{State budget calls for $10 \%$ research cut}

With a $10 \%$ permanent reduction in state financial support for University research, the state's fiscal 2002-03 budget calls for a $\$ 32$ million cut in UC's organized research funding (see p. 178). The across-the-board cut was among several targeted reductions specified for the University. Overall, the state is providing $\$ 3.2$ billion for $\mathrm{UC}^{\prime}$ s operating budget in 2002-03, about $3 \%$ less than last year.

The cut in organized research affects programs throughout the University, including those conducted by the Agricultural Experiment Station (AES) at the Berkeley, Davis and Riverside campuses. Also included are AES funds managed through the Office of the Vice President in the Division of Agriculture and Natural Resources (ANR).

The Division's senior administrators expect the impact of this budget reduction to be substantial and long-lasting. "State agencies have been asked to plan for a $20 \%$ reduction in funding for 2003-04," says W.R. Gomes, ANR vice president. "The University budget and that of ANR will no doubt sustain further reductions, beyond those taken in 2003-04. The extent of these reductions is unpredictable at this time."

This cut is "relatively harsher" for the Division than it might seem at first blush, notes ANR associate vice president Henry Vaux Jr., because "we have never recovered financially from the severe budget cuts of the early 1990s." Like Gomes, Vaux doesn't expect the fiscal situation to improve soon. "The bottom line is we anticipate that there are going to be even larger cuts next year - and the reserves that helped buffer the impact of this year's cuts are gone," he says.

\section{UC offers online course for grape pest advisors}

Faced with increasingly stringent environmental regulations - including more rigorous state licensing requirements that go into effect Jan. 1, 2003 - pest control advisors (PCAs) for grapes can now obtain important information in a new online course developed by the UC Davis-based Sustainable Agriculture Research and Education Program (SAREP).

"Ecological Pest Management in Grapes" is the first online course of its kind in California, and per- haps the nation, that is completely Web-based and has undergone scientific peer-review, says Chris Geiger, California Department of Pesticide Regulation (DPR) entomologist. Geiger, formerly of SAREP, created the course with SAREP education coordinator David Chaney, in consultation with an advisory committee of UC scientists and grape PCAs. "As environmental regulations become tighter and older pesticides are removed from the market or heavily restricted, many growers are modifying their production systems to include more ecologically based approaches to controlling pests," Chaney says.

Pest management professionals can play a key role in this transition process, providing clients with information on the biology of pests and natural enemies, sampling programs, decision support tools and knowledge of softer, less disruptive pest control materials.

By making use of up-to-date educational technologies, the self-guided course offers a highly interactive educational experience. It includes inquiry-based, problem-solving simulations, and interactive self-tests.

The course covers the biology of spe-

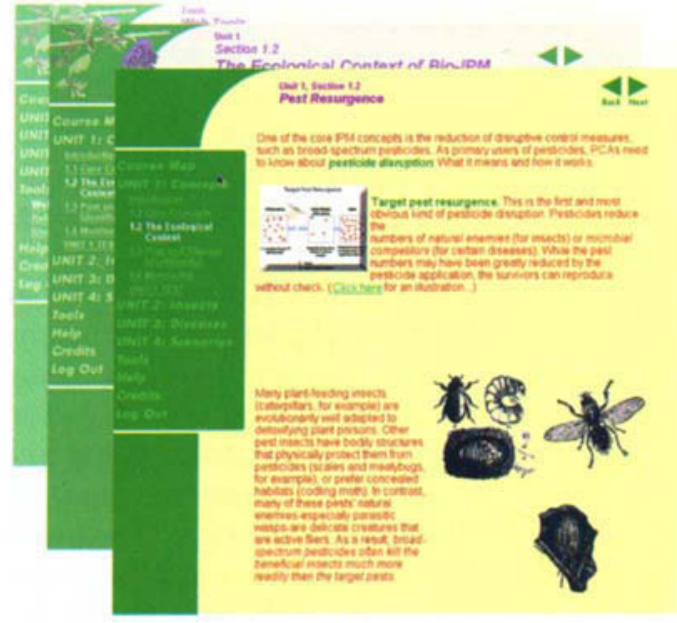

Grape pest advisors have a new educational tool the first online course that has been peer reviewed by UC scientists. "Because it's on the Web, students can progress at their own pace," says Chris Geiger of the California Department of Pesticide Regulation, who co-developed the program. cific organisms in the grape ecosystem, field diagnosis and monitoring techniques and summaries of the best available decision-making tools and management options. Graded multiple-choice exams are taken online, and are used to determine the number of continuing education credits students receive.

The course advisory committee included: Jenny Broome, SAREP associate director; Clifford Ohmart, Lodi-Woodbridge Winegrape Commission; Kent Daane, UC Berkeley Extension assistant specialist; Rhonda Smith, viticulture farm advisor, UCCE Sonoma County; Mary Louise Flint, publications director, UC Integrated Pest Management Program; Larry Whitted, PCA; and George Leavitt, viticulture farm advisor, UCCE Madera County. For more information, go to: www.sarep.ucdavis. edu/ courses/grapes.

- Compiled from UC and other news sources 